\title{
Handling Qualities Implications for Crewed Spacecraft Operations
}

\author{
Randall E. Bailey \\ NASA Langley Research Center \\ 24 W. Taylor St \\ Hampton, VA \\ 757-864-8682 \\ randall.e.bailey@nasa.gov
}

\author{
E. Bruce Jackson \\ NASA Langley Research Center \\ 24 W. Taylor St \\ Hampton, VA \\ 757-864-4060 \\ bruce.jackson@nasa.gov
}

\author{
J.J. (Trey) Arthur \\ NASA Langley Research Center \\ 24 W. Taylor St \\ Hampton, VA \\ 757-864-6609 \\ trey.arthur@nasa.gov
}

\begin{abstract}
Handling qualities embody those qualities or characteristics of an aircraft that govern the ease and precision with which a pilot is able to perform the tasks required in support of an aircraft role. These same qualities are as critical, if not more so, in the operation of spacecraft.

A research, development, test, and evaluation process was put into effect to identify, understand, and interpret the engineering and human factors principles which govern the pilot-vehicle dynamic system as they pertain to space exploration missions and tasks. Toward this objective, piloted simulations were conducted at the NASA Langley Research Center and Ames Research Center for earth-orbit proximity operations and docking and lunar landing.
\end{abstract}

These works provide broad guidelines for the design of spacecraft to exhibit excellent handling characteristics. In particular, this work demonstrates how handling qualities include much more than just stability and control characteristics of a spacecraft or aircraft. Handling qualities are affected by all aspects of the "pilot-vehicle dynamic system," including the motion, visual and aural cues of the vehicle response as the pilot performs the required operation or task. A holistic approach to spacecraft design, including the use of manual control, automatic control, and pilot intervention/supervision is described. The handling qualities implications of design decisions are demonstrated using these pilot-in-the-loop evaluations of docking operations and lunar landings.

\section{TABLE OF CONTENTS}

1. INTRODUCTION

2. BACKGROUND .1

3. PRoXimity OPERATIONS AND DoCKING .........2

4. LUNAR LANDING HQ IMPLICATIONS..............6

5. HANDLING QUALITIES FOR AUTOMATION ....16

6. CONCLUDING REMARKS...............................17

REFERENCES.................................................17

ACKNOWLEDGEMENTS........................................19

BIOGRAPHIES.................................................19

\section{INTRODUCTION}

Handling qualities embody those qualities or characteristics of a vehicle that govern the ease and precision with which a pilot is able to perform a required task or operation [1]. These same qualities are as critical, if not more so, in the operation of spacecraft [2].

The requirement that manual control be provisioned is codified in NASA's Human-Rating Requirements for Space Systems [3]. Under Item 3.4.1, "The crewed space system shall provide the capability for the crew to manually control the flight path and attitude of their spacecraft..." This requirement was established as "a fundamental element of crew survival. Manual control means that the crew can bypass the automated guidance of the vehicle to interface directly with the flight control system to effect any flight path within the capability of the flight control system."

Further, under Item 3.4.2, "the crewed spacecraft shall exhibit Level 1 handling qualities (Handling Qualities Rating (HQR) 1, 2 and 3), as defined by the Cooper-Harper Rating Scale, during manual control of the spacecraft's flight path and attitude." The primary rationale is that Level 1 handling qualities will allow the crew to effectively control the spacecraft when necessary for mission completion or to prevent a catastrophic event.

These requirements are sufficient motivation to properly attend to the design of inherently good spacecraft handling qualities. However, the depth and breadth implicit in these requirements is not often appreciated.

Handling qualities are not defined only by the control system design characteristics of the vehicle; they also include the motion, visual and aural cues of the vehicle response. This influence spans across the design of the manual and automatic control modes, cockpit displays, control inceptors (e.g., tactile cueing), crew station design, crew resources management (including mission control) and mission operations.

A holistic approach to spacecraft design, including the use of manual control, automatic control, and pilot intervention is outlined to ensure excellent handling qualities. Spacecraft handling qualities research is described which highlight the implications of handling qualities on spacecraft design and operations and capture pertinent lessons-learned for future vehicles, including commercial crew vehicles. 


\section{BACKGROUND}

Handling qualities are illustrated using the concept of the "pilot-vehicle dynamic system" (Figure 1); the elements of which form a closed-loop system, driven by a piloting task or mission objective. The pilot acts as the system controller. The pilot's role is to serve as "the decision-maker of what is to be done, the comparator of what's happening vs. what he wants to happen, and the supplier of corrective inputs to the aircraft controls to achieve what he desires" [4].

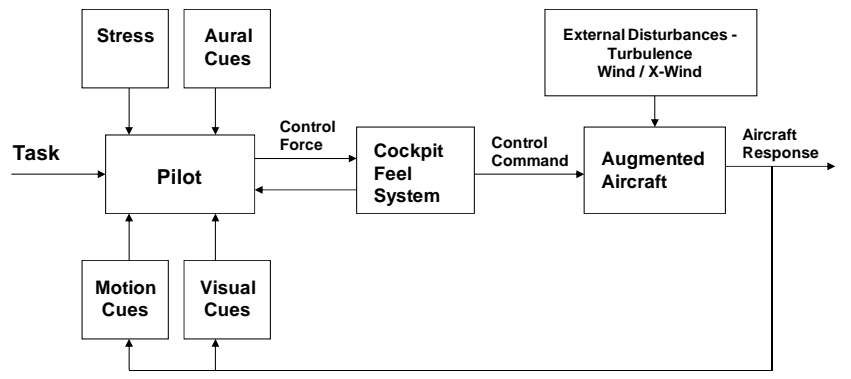

Figure 1: Pilot-Vehicle Dynamic System [4]

Handling qualities reflect the precision with which the pilot can accomplish the given task (as the controller of the closed-loop system) and the associated pilot workload and compensation to meet this level of performance. Although the "augmented aircraft" - the vehicle's dynamic response characteristics augmented by its flight control system would logically be the primary determinant of handling qualities, the other system factors may be equally influential. These cues (such as the presence or absence of motion cues and the environment, e.g., external visibility, control upsets, aural cues, and pilot stressors) are the feedbacks that the pilot uses to perceive the vehicle response and meet the demands of the task.

Modifications or changes in individual elements within this closed-loop system may be compensated by the adaptive pilot, but possibly at a cost of pilot workload or changes in task performance. These effects cannot be segregated; thus, handling qualities must really be evaluated in the aggregate $[4,5]$. Empirical and historical data can provide perspective and estimates on the effects of changing elements within the system but the only truly accurate measure is to evaluate the aggregate closed-loop system.

\section{Spacecraft Handling Qualities}

Our foundational understanding of handling qualities (HQ) and the pilot-vehicle dynamic system is rooted in the aeronautics domain. Although the physics of the systems are obviously different, the fundamentals are no different and of no less importance for spacecraft.

The National Aeronautics and Space Administration (NASA) initiated a multi-centered Spacecraft Handling Qualities project in 2007. This project was designed to provide data and guidelines for the design, development, test, and evaluation of NASA's Constellation Program platforms as well as all future NASA and other government agency and commercial spacecraft.

This work was spurred on, in part, by the legacy established by Gemini and Apollo where significant research was conducted for the parametric investigation of what drives spacecraft handling qualities. The Apollo and Gemini work investigated, for example, the handling qualities influence of such parameters as:

- Spacecraft attitude control mode, control power, target lighting and target oscillatory motion $[6,7]$;

- "Remote" docking using closed-circuit television [8];

- Visual aids, in day and night conditions, to align to a docking target [9];

- Hand controllers, instruments, and control modes [10];

- Visual simulation compared to "full-size" docking [11];

- Visual aids and attitude control modes in lunar orbit [12];

- Handling qualities design requirements and control law types for lunar landing $[13,14]$.

For Apollo and Gemini, this work was critical since experience for the required spacecraft operations was nonexistent.

One could argue that a wealth of data and experience are at hand today so new work in spacecraft handling qualities is not needed. The counter argument is that there is not a sufficient basis from which to extrapolate to new vehicles, operations, and operating conditions and mission plans. As an example, when the Space Shuttle was being developed, proximity operations and docking issues were assumed to be a lower priority (i.e., had less technical risk) compared to other system development tasks because of the Apollo and Gemini legacy [15]. This lack of initial concern for proximity operations and docking resulted in "complex operational work-arounds over the life of the [Shuttle] program." Stepping back and fully considering the past is the only way to avoid reliving history.

To avoid reliving this past, a research, development, test, and evaluation process was initiated to identify, understand, and interpret the engineering and human factors principles which govern the pilot-vehicle dynamic system (i.e., handling qualities) as they pertain to space exploration missions and tasks for Constellation and all future NASA and other government agency and commercial spacecraft.

\section{Proximity Operations AND Docking}

The Spacecraft Handling Qualities work initially investigated proximity operations and docking issues, principally focused around two human-in-the-loop experiments each, conducted at both the Ames Research Center (ARC) and Langley Research Center (LaRC). Subsequent to this work, additional activity was conducted at NASA Johnson Manned Space Flight Center, focused 
specifically on Orion/Crew Exploration Vehicle handling qualities investigations [16].

These works revealed numerous design implications and design guidance which capture the influence of handling qualities on a spacecraft design for proximity operations and docking.

\section{Piloting Task}

A complete task definition is required, not just of the primary control task, but also of any critical auxiliary tasks. For proximity operations and docking, it was repeatedly stressed by Shuttle commanders that the docking task is a crew effort. Delegation of tasks across the crew was required. In lieu of this - for our single pilot evaluations automation was added to replicate some of these crew functions, such as using a "range to docking" automated call-out. Task analysis should be conducted to appropriately define the "complete" piloting task; otherwise, false or misleading assessments may result.

The concept of operations for rendezvous, proximity operations and docking, including docking mechanisms, are first-order influences on handling qualities and the resultant on-orbit control design. This fact is self-evident because an evaluation pilot is rating the vehicle's handling characteristics for a given task or mission task element.

In conducting handling qualities evaluations, the criticality of the designing appropriate tasks cannot be overemphasized. History has shown that latent handling qualities deficiencies are exposed by using piloting tasks that create "stress cases" - those conditions that necessitate closed-loop control of the vehicle to achieve the task objective. The task should not be unreasonable, but it is usually one which would not often occur. An example in the aviation domain is the offset landing task. This task is within the capabilities of the aircraft and is "legal" to perform, but operationally, pilots will usually perform a go-around rather than correcting back to the centerline of the runway in an attempt to land. Using this task to evaluate handling qualities exposes the pilot-vehicle dynamic system to a high bandwidth task for the purposes of exposing potentially latent deficiencies.

In proximity operations and docking, this same approach was used. The initial condition on a +V-bar docking approach to the International Space Station (ISS) was offset by $2.5 \mathrm{ft}$ from the docking axis $[17,18]$. This offset required the evaluation pilot to laterally and vertically reacquire the docking axis. This "stress case" was validated as a good HQ task by experienced Shuttle commanders as one that stressed closed-loop control without completely diverging from the concept of operations. Operationally, this task mirrors the aviation-domain offset landing task where the offset is at the edge of the allowable ISS docking corridor that would likely, but not necessarily, require the vehicle to stop the approach and reposition before attempting docking.

\section{Desired and Adequate Performance Standards}

Equally critical to the task definition are the required task performance standards. The performance standards must be: a) germane to the required operation or task as they apply to the actual mission; b) include variables or outcomes controllable by the pilot; c) observable to the pilot; and, d) sufficiently demanding that high closed-loop pilot-vehicle "task bandwidth" is required to aptly stress and test the handling qualities characteristics [2].

Once the task is defined, ensuring that closed-loop control by the pilot is required, the "task bandwidth" is modulated by: 1) the precision that is demanded of the pilot-vehicle performance; and, 2) the time to complete the task.

1) Task Performance-The task precision is dictated by the mission. For proximity operations and docking, desired and adequate docking performance standards were established based on the anticipated docking hardware, as shown in Table 1 . The adequate docking standard was defined by the successful docking performance limits. Adequate performance means that the task can still be accomplished; albeit, without significant margin for error. On the other hand, desired performance means that the task can be accomplished with significant margin. Changing the docking method, changes the task and hence, the handling qualities issues and design challenges.

2) Time Constraint-A time constraint may be inherent for certain tasks. If it is not naturally part of a task, it must be imposed; otherwise, this becomes an uncontrolled variable in the task that can result in potentially adverse consequences.

For proximity operations and docking, a time constraint was established by specifying an approach and docking closure rate (e.g., $0.1 \mathrm{ft} / \mathrm{sec}$ ). This closure rate was included as part of the desired and adequate performance standards. The desired performance standard was met if the closure rate for the duration of the task was held within $\pm 25 \%$ of the target value. The adequate performance standard was within the expected performance limits of the docking mechanism.

\section{Table 1: Docking Task Performance Standards}

\begin{tabular}{|l|l|l|}
\hline & $\begin{array}{l}\text { Desired } \\
\text { Performance }\end{array}$ & $\begin{array}{l}\text { Adequate } \\
\text { Performance }\end{array}$ \\
\hline \hline Radial Offset & $\pm 1.5 \mathrm{in}$ & \pm 1.5 to $\pm 3.2 \mathrm{in}$ \\
\hline $\begin{array}{l}\text { Roll/Pitch/Yaw } \\
\text { Angle }\end{array}$ & $\pm 2.0 \mathrm{deg}$ & \pm 2.0 to $\pm 3.0 \mathrm{deg}$ \\
\hline $\begin{array}{l}\text { Axial Closure } \\
\text { Rate }(0.1 \mathrm{ft} / \mathrm{s})\end{array}$ & 0.075 to $0.125 \mathrm{ft} / \mathrm{s}$ & 0 to $0.075 \mathrm{ft} / \mathrm{s} \mathrm{OR}$ \\
\hline $\begin{array}{l}\text { Radial (Linear) } \\
\text { Rate }\end{array}$ & $\pm 0.0325 \mathrm{ft} / \mathrm{s}$ & $\begin{array}{l} \pm 0.0325 \mathrm{to} \\
\pm 0.1125 \mathrm{ft} / \mathrm{s}\end{array}$ \\
\hline $\begin{array}{l}\text { Roll/Pitch/Yaw } \\
\text { (Angular) Rate }\end{array}$ & $\pm 0.05 \mathrm{deg} / \mathrm{sec}$ & $\begin{array}{l} \pm 0.05 \mathrm{to} \\
\pm 0.15 \mathrm{deg} / \mathrm{sec}\end{array}$ \\
\hline
\end{tabular}


The required HQs are thus established by the precision within which the task must be completed for mission success. These standards were based on data relative to the anticipated docking mechanisms for Constellation and those anticipated for the commercial off-the-shelf platforms [19]. If the docking mechanism or operational concepts are changed, the HQ standards and design challenges will also change.

\section{Handling Qualities Influences}

One predominate handling qualities factor in proximity operations and docking is the rotational coupling of the vehicle due to translational inputs $[17,18]$. This effect is illustrated in Figure 2 using a simplistic example where the relationship between reaction control system (RCS) jet longitudinal location varies with respect to the vehicle center-of-mass (CM). If the RCS jet is at the same $\mathrm{x}$-axis (body) position, translational RCS jet firings pass through the $\mathrm{CM}$ and do not introduce spacecraft rotation changes (i.e., uncoupled or "neutral coupling"). The left- and righthand sketches in Figure 2 place the RCS jets forward or aft of the CM x-axis (body) position so translational RCS jet pair firings introduce either "adverse" or "proverse" spacecraft rotation changes, respectively. For a configuration with adverse coupling, a command to translate the vehicle right would cause an initial yaw to the left (as viewed through the centerline camera), seemingly counter to the translation command. Conversely, in a case with proverse coupling, a command to translate right would effect a yaw rotation in the right direction (as viewed through the centerline camera), but seemingly additive to the translation command. This coupling effect may also occur in the lateral translation/yaw rotational axes as well.

\section{Six Degree-of-Freedom (6 DOF) Control HQs}

Rotation coupling effects were investigated during Apollo and Gemini and careful RCS design enabled successful manual control of proximity operations and docking.

These issues were reevaluated with representative currentday RCS thruster sizes [17]. The HQ data show that desired performance can generally be obtained without coupling, but six degree-of-freedom (6 DOF) control is higher workload and thus, not satisfactory without improvement (not Level 1 HQRs). Adequate HQ performance (Level 2 HQRs) is generally possible within the range of coupling effects evaluated. Large pulse widths (minimum RCS jet firing times) and large thruster sizes, coupled with adverse rotational coupling can create Level 3 HQRs. Coupling was correlated (statistically significant) to fuel usage; lower coupling resulted in better HQRs and less fuel being expended in the operation.

For instance, on occasion, the desirability or need for manual rotational (6 DOF) control was questioned; however, the more senior Shuttle commanders quickly dispelled any movement toward eliminating this capability. Their experience showed that, while not often used, manual rotational control enabled many orbital Shuttle missions.

\section{Three Degree-of-Freedom (3 DOF) Control HQs}

The introduction of rate command/attitude hold (RCAH) control laws to maintain spacecraft attitude (allowing the pilot to perform translational inputs only) can significantly, but not completely obviate rotational coupling effects. Coupling effects may still be apparent as the vehicle slices through the selected attitude hold deadbands $[18,19]$.

As one pilot observed, the "vehicle is ... going to hold attitude plus or minus the deadbands, but I don't feel like I'm really in control." Pilot compensation was either to: a) ignore the deadbands (there were cockpit indications of imminent deadband-limit RCS firing); b) offset the docking alignment in anticipation of a deadband firing; or, c) correct for them immediately when they occur. In either case, a handling qualities penalty is incurred, resulting in a net improvement in HQRs for 3 DOF control, but not "nightand-day" differences [17].

\section{Feedforward Compensation}

Pulse-width-modulation-type feedforward compensation can actuate RCS firing durations and combinations to reduce residual RCS translation-to-rotational coupling effects $[20,21]$.

Pilot-in-the-loop testing vividly demonstrated the benefits of these systems. Feedforward compensation provided Level 1 HQRs by virtually eliminating translational-rotational coupling effects [20].

Handling qualities tests were performed with feedforward compensation in both nominal and off-nominal conditions such as with intentionally introduced inaccuracies or impurities associated with the controller (e.g., by offsetting the $\mathrm{CM}$ from the design position, varying the thruster output from nominal value, etc.). In all cases tested, the feedforward compensator handling qualities were largely unaffected [21].

Further failure mode effects testing is needed, however. The concern is the handling qualities "cliff" that may be lurking. Particular emphasize should include the real-world effects of thruster size and cycle times and how these issues manifest themselves into residues from perfect compensation and latencies caused by duration times to complete the pulse width commands. The hope is that the control law compensation will be robust and not prone to any catastrophic degradation of handling qualities due to these effects or others. 


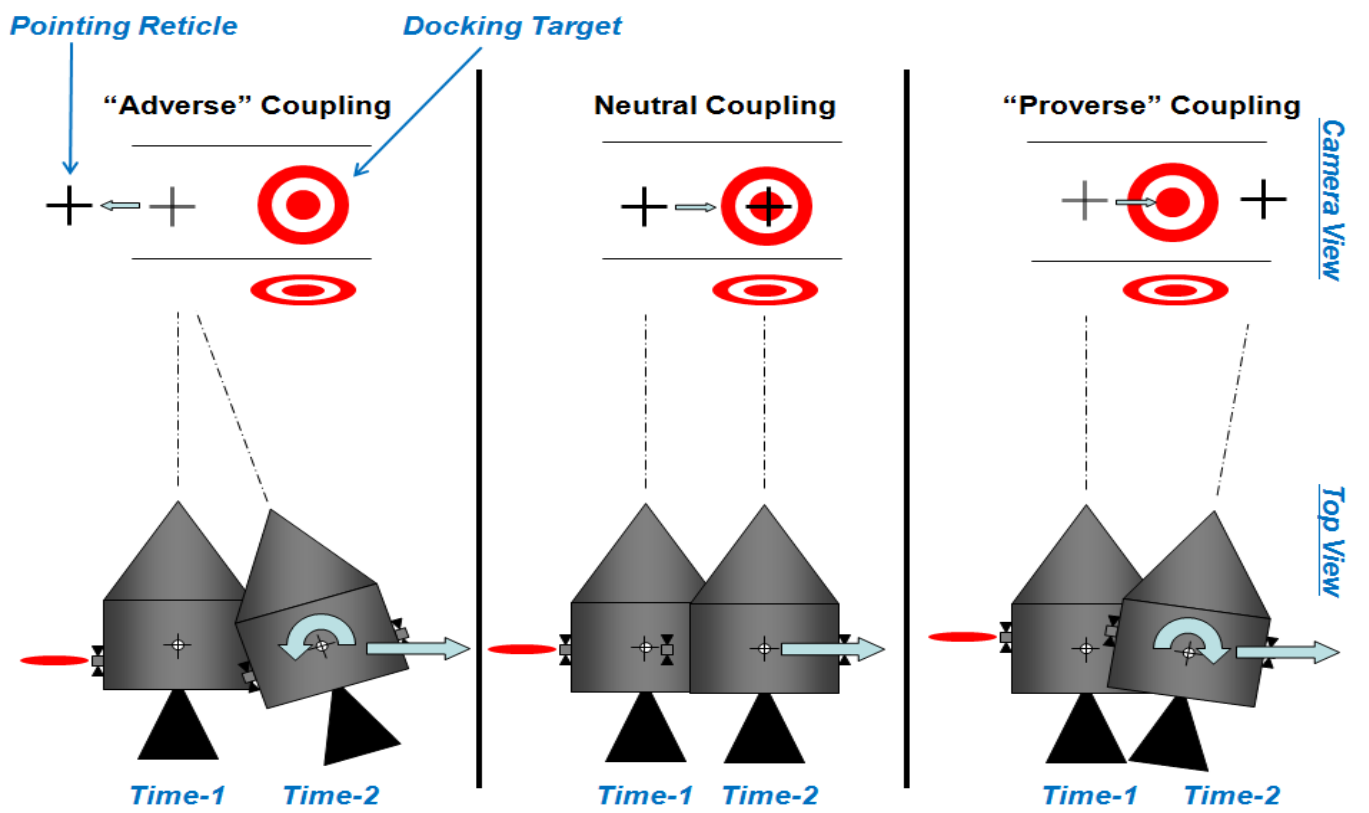

Figure 2: Illustration of Adverse, Neutral, and Proverse Translational-into-Rotational Coupling

\section{Fuel Consumption}

The rotational-translational coupling effects influence fuel consumption in two ways. First, fuel consumption is driven by the design of a control law compensator that might minimize the coupling effects (e.g., RCAH vs. feed-forward controller). Second, the rotational coupling (i.e., handling qualities) affects the number of translational inputs required for the task [20,21]. Larger attitude deadbands for an RCAH controller uses less fuel in compensating for rotationaltranslational coupling due to translational inputs than smaller deadbands. Analogously, the feedforward compensator uses more fuel than a typical RCAH controller. However, testing showed that during the task, a properly designed feedforward controller used less overall fuel than an RCAH design because the pilots used fewer translational inputs. The predictability of the system and fewer deadband firings resulted in overall less fuel expenditure during the task [20]. The net result is that better handling qualities corresponded to less propellant consumed.

\section{Display / Aiding Information}

Various display information methods have been attempted to compensate for rotational-translational coupling effects $[20,21]$. Each have varying degrees of success, none major and few with consensus of opinion. The most successful of these are the deadband indicators - explicitly showing the crew the attitude (and rate) at which a deadband in the RCAH controller will fire. Translational rate and positioning information with respect to the docking Local Vertical Local Horizontal (LVLH) axis was also put to excellent use.
But by far, the preeminent display factor influencing these evaluations was the docking camera. Evaluations were not flown without the docking camera or with boresight or parallax issues, but its critical role in the task/mission was apparent. The importance of visual aids for docking alignment was established in Gemini/Apollo and design provisions were made accordingly [9]. The appropriate provisions must be ensured in future spacecraft designs either by redundancy in the event of a camera failure or alternate positioning aids.

\section{Task Influences}

Apollo and Gemini docking used much higher closure rates than the $0.1 \mathrm{ft} / \mathrm{sec}$ standard used by Shuttle (nearly an order of magnitude). The reasons are many (different docking mechanisms and an almost order of magnitude mass difference between Gemini/Apollo and Shuttle), but they may not hold true in future operations.

An evaluation of docking closure rate was conducted using $0.5 \mathrm{ft} / \mathrm{sec}$ closure starting at $50 \mathrm{ft}$ from the docking port with an initial $2.5 \mathrm{ft}$ offset from the approach corridor [17]. The handling qualities effects are illustrated in Figure 3, using a "bubble" chart where each HQR is shown and the size of the HQR bubble is proportional to the number of ratings at that level.

With a RCAH holding the docking attitude, the higher closure rate task produced generally worse HQRs, but not dramatically so. Adequate, if not desired docking performance was the norm. However, with 6 DOF control and rotational due to translational coupling, ratings of 10 were generally given. At these higher closure rates, "you don't have enough time to be messing around with all these 
kind of control inputs that you have to do." Potentially catastrophic consequences could result.

\section{Rotating Targets}

Current low earth operations to the ISS provide stationary or quasi-stationary docking targets. Future docking requirements may involve rotating targets, especially in case of attitude control failures resulting in an uncooperative target vehicle.

Evaluations of docking attempts with rotating targets showed this was possible, but the pilot workload was not tolerable [21].

The pilots demonstrated amazing adaptability to the various configuration effects and targets but an overwhelming need for reconfigurable digital autopilot control (DAP) was voiced. The ability to tailor the DAP gains and modes, in terms of pulse size, direct vs. pulse, and segregated, selectable modes per axis (rotational and translational), were critical to success.

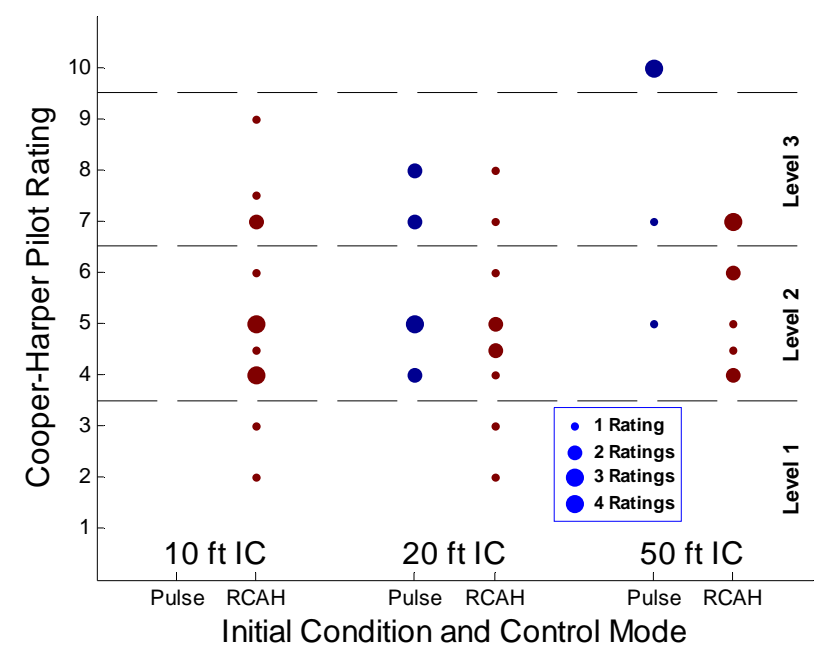

Figure 3: Effect of Tasking Differences on HQRs

\section{LUNAR LANDING HQ IMPLICATIONS}

The holistic design (and impact) of handling qualities on a spacecraft design is illustrated in the following, using the design and results of a piloted simulation of a lunar landing vehicle.

\section{Lunar Lander Handling Qualities Design Implications}

As NASA looked to return to the lunar surface, the design issues and lessons-learned of Apollo were closely studied as they are still relevant today for practical planetary and lunar lander vehicle designs and missions [22-27]. From this baseline, additional challenges for the vehicle design were levied to improve the scientific return for manned lunar missions.
- Missions were slated toward the scientifically interesting lunar polar regions, unlike the equatorial landing sites of Apollo.

- Missions were to be flown "any time."

- A lunar habitat and a sustainable infrastructure would be developed for an enduring scientific presence.

These mission objectives created several design constraints relevant to the handling qualities, and ultimately, the vehicle's design:

1) In the polar region, the very low sun angles create visually powerful shadow effects that cause the loss of natural vision depth cues and impair translational velocity and landing zone awareness.

2) Operations would be independent of the landing zone lighting conditions (unlike Apollo, where "optimal" lighting was designed by the timing of the launch).

3) Habitat build-up constrains the landing approach procedures and dictates much higher landing accuracy than Apollo.

These design constraints further define the operational task or mission task elements which the vehicle's handling qualities and consequently, the spacecraft design:

a) Landing precision is dictated by the proximity to a habitat build-up; no "overflight" is permitted.

b) Minimum fuel consumption is preeminent.

c) Natural vision may or may not be useful to the pilot/crew.

d) Approaches to the landing site will need an out-ofplane maneuver (such as a "dogleg" approach) to minimize collateral damage to the habitat from the descent module in the event of a landing abort (with subsequent staging of any descent hardware).

The lack of natural vision references for the pilot/crew is both a blessing and a curse. During Apollo, the constraints placed by the design of the Lunar Module (LM) window for crew visibility and landing trajectory were "a major problem" [22]. Apollo used a "pitch-up" maneuver in the final approach descent and landing phase and a judiciously designed window configuration to enable the flight crew to have approximately two minutes of viewing of the planned landing site. The pitch-up sacrificed fuel usage by rotating the vehicle to a near vertical orientation, so the crew could see and verify the integrity of the landing site (e.g., free of rocks and debris, terrain slope within design allowances) through a window that provided almost 70 deg nose-low visibility. Optimal visibility conditions were provided by operational procedures and constraints, including launch times, dates, and landing locations.

Automated landing of Apollo was possible, but all landings were manually flown with the crew taking over control between 550 and $240 \mathrm{ft}$ above the touchdown zone elevation [26]. After Apollo 11, each crew performed at least 1, and 
as many as 18 , landing zone re-designations during the pitch-up phase [27].

Technologies developed since Apollo offer potential ways to break some of the aforementioned Apollo operational and design constraints as well as meeting the new Exploration challenges. For instance, Synthetic and Enhanced Vision (SV/EV) technologies, conceived and developed in the aviation domain, may eliminate the challenges imposed by a natural vision constraint and thus, enable additional benefits for safer, more efficient operations [28]. These technologies are being used, in whole or in part, under the Autonomous Landing and Hazard Avoidance Technology (ALHAT) [29].

$\mathrm{SV} / \mathrm{EV}$ technologies offer the possibility that fuel-expensive Apollo-like pitch-up maneuvers would be unnecessary using "equivalent vision" instead [30]. SV/EV technologies can provide equivalent visual information sufficient for the crew to obviate the impact of landing zone obscurants and be independent of window sizes and placements, visual illusions, or lighting/depth perception conditions.

These challenges exist within the broader context of manual control, handling qualities, and the engineering design tradespace for a Lunar Landing vehicle.

\section{Lunar Lander Handling Qualities Design}

A piloted simulation study investigated the handling qualities of a lunar landing vehicle and the influence of critical design issues with operational employment consequences. The focus was on visual cueing and control effector sizing during manual control of the approach and landing of a lunar landing vehicle, enabling a quantification of the trade-space for the vehicle design and operational deployment. Automatic control modes of the vehicle were a recognized design feature of future lunar lander vehicles; the implications of which are discussed in Section 5.

Control Laws-RCAH control laws with a phase-plane controller were evaluated. Other control law methods were rejected for evaluation:

- Translational control using the RCS, while precision control is offered, will typically be underpowered and thus, not conducive to minimum fuel/minimum fuel objectives [31].

- Thrust vectoring control (TVC) of the descent engine [32] offers excellent control power, but is critically flawed due to potential failure modes. Apollo evaluated this concept but rejected it, limiting TVC rates to provide trim control to avoid catastrophic TVC actuator failure consequences [33].

- More sophisticated control methods such as translational rate command-position hold functions were dismissed because, while excellent performance has been demonstrated in rotorcraft applications and elsewhere [34], they lack in simplicity of design. They also can suffer from the human-centered design principles since, with only one-sixth gravity, this method requires very large attitudes for rate or position hold functions. Elaborate display and alerting functions would be needed for the crew to appropriately monitor normal operations and provide timely intervention and recovery in event of failures.

Control Power- "Satisfactory" and "Acceptable for Emergency Operations Only" handling characteristics guidelines for rotational control effectiveness, using the Cooper rating scale [35] emerged from the Apollo data [36]. The criterion, for a RCAH control law, boils down to: 1) the maximum rotational acceleration authority; and, 2) the chosen maximum rate command provided to the pilot.

The maximum rotational acceleration authority is approximately the RCS jet size, multiplied by the number of RCS jets and their moment arm and divided by the rotational inertia. Part of the HQ design trade-space can be illustrated using the Apollo LM experience. For Apollo, the criteria were met when four RCS jets were used. Nominally, however, only two jets were fired to conserve RCS propellant but for circumstances that dictate higher rotational control (e.g., excessive rate error in the RCAH control law), four jets were available [13]. Apollo also placed the RCS jets on the ascent module. This placement increased the moment arm (increased rotational effectiveness). It also increased the LM ascent mass. The RCS jets were also used for on-orbit attitude control. This obviated the need to have two sets of RCS jets (one for descent; one for ascent and on-orbit) but the LM RCS jets, sized for the landing mission, were found to be too large for on-orbit operations, causing proximity and operations HQ issues [37].

The present-day concern is that the rotational control effectiveness required to meet the Apollo guidelines are significantly larger than what current designs may practically provide. Validation of the guidelines is needed and possible alternative methods to satisfy handling qualities should be explored.

NASA Ames has recently conducted two Vertical Motion Simulator tests evaluating the validity of these rotational control effectiveness criteria from Apollo [31,38]. Evaluations were conducted using a 15 degree (deg) glideslope trajectory to a pitch-up for vertical landing, mirroring the initial Apollo lunar landings. The term "glideslope" is used throughout as an analogy to the aeronautics domain, where a constant approach angle to landing is flown. In this application, a constant angle approach is only approximate; the trajectory curves from the initial approach angle to smoothly transition to a hover point above the landing zone, transitioning to a vertical descent to landing.

Testing was conducted with and without explicit pitch, roll, and rate-of-descent guidance commands shown on headdown displays. Testing was planned to vary the evaluation task, flying with and without a $250 \mathrm{ft}$ lateral offset/dog-leg approach from the initial trajectory to the vertical landing. 
However, pre-test work showed that, without explicit guidance, the evaluation pilots could not reliably complete the task with a lateral offset. For the no-guidance test cases, only a straight-in task was flown.

For the lateral offset task with guidance, the Apollo design guidelines were roughly supported. But for a straight-in task, without an offset, the degradation of handling qualities with decreasing control authority was not strongly supported.

In the second test, the characteristics of the Lander Vehicle were changed, but the major elements of the test were replicated.

A summary plot of the data against the guidelines is shown in Figure 4. The plot uses median HQRs for the twelve evaluation pilots. The trends generally follow the first simulation test results. At the highest levels of control power tested, median Level 1 pilot ratings were generally given. The individual rating data, however, exhibits substantial scatter. Some Level 3 or nearly Level 3 ratings were given for those configurations with median Level 1 ratings. The rating scatter warrants concerns since this suggests the possibility of lurking cliff-like HQ characteristics where Level 1 handling characteristics can quickly degrade due to the presence of system nonlinearities, latency, or handling characteristics inappropriately sensitive to pilot techniques [38].

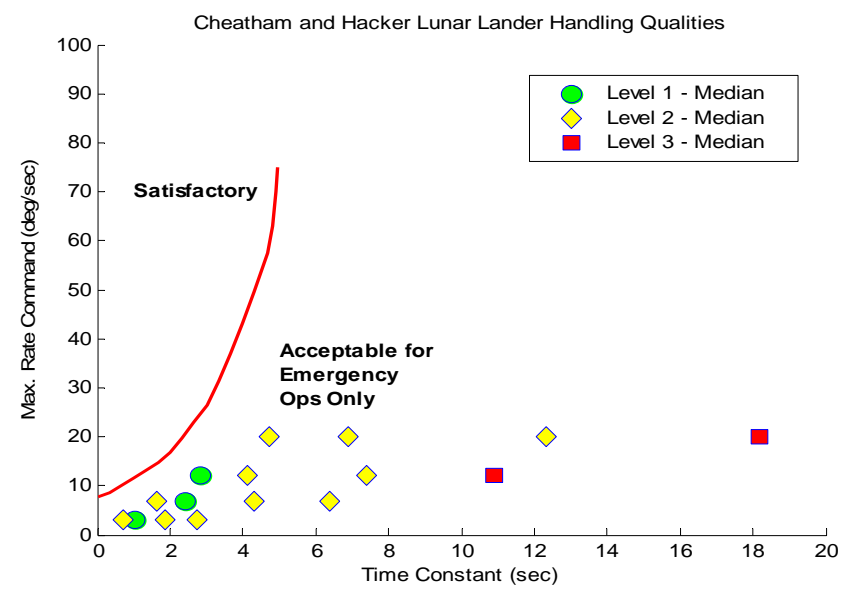

Figure 4: HQR Level Data [38] vs. Guidelines [13]

\section{Test Description}

A pilot-in-the-loop simulation was conducted to explore the control and display interactions on the handling qualities of a lunar lander vehicle.

This work built upon the previous work [31,38] but explored the control and display interactions in a lunar lander design.

First, the previous work evaluated only shallow 15 deg glideslope trajectories to the landing zone. This trajectory angle was flown for the initial Apollo LM missions, but the later so-called "J" missions used trajectories approaching 25 deg glideslope. Future vehicles may find it advantageous to use higher glideslope angles to landing [39]. Trajectory design is part of the trade-off in fuel consumption and natural vision viewing of the landing site.

Second, the previous work provided for and allowed the use of direct translation control by the pilot using a translational hand controller. Although the control authority was minimal, it was permitted and introduced a degree-offreedom which differed from Apollo. In Apollo, only rotational attitude control to effect translational positioning was used because of the significant amount of rotational coupling introduced by translational control inputs. The RCS jets were located on the Ascent Module for maximum rotational control authority. Evaluations were conducted without allowing direct translational control for comparison.

Finally, the critical influence of visual cues was considered. As the trajectory approach angle is changed, the pitch attitude will vary; thus, affecting the amount of time that the crew can use for natural vision viewing of the landing site. The previous work showed that manual flight to an offset landing zone was not possible. One might consider that this result was because the out-the-window simulated visual cues were insufficient to support the task (as discussed later). On the other hand, the visual cues might have been sufficient but the control characteristics were deficient. In any event, the influence of natural vision and the potential of "equivalent vision" technologies warranted exploration. Equivalent vision may represent a new tool in the manned planetary exploration designers" "tool-bag."

These experimental objectives were evaluated in the context of variations in the control authority of a lunar landing vehicle which uses a RCAH control law, analogous to the guidelines developed under Apollo.

\section{Simulated Spacecraft}

A simulation model (Figure 5) was built based on evolving lunar lander designs [32].

The simulation model was built using object-oriented programming techniques within the Langley Standard Realtime Simulation in $\mathrm{C}++\quad(\mathrm{LaSRS}++)$ software framework [40]. A generic-spacecraft simulation within this framework served as a test bed for modeling spacecraft dynamics, propulsion, control systems, guidance, and displays.

The vehicle model was composed of interconnected stages, simulated using a parent/child relationship. The ascent stage was modeled as the parent with the descent stage as a child. The descent stage contained separate mass models for the main engine fuel, RCS fuel, and the airlock. Force models were provided for the main engine, each of the sixteen RCS engines, and the four landing gear models. For simplicity, the throttle-able, thrust output of the main engine force 
model was placed close to the lateral and horizontal axes of the stacked center-of-mass. Active gimbaling of the main engine was provided to trim the thrust vector through the CM. All forces and moments were applied to the stacked vehicle's center of mass. Fuel slosh was not modeled.

The pilot, as defined by the design eye point reference (DERP), was located $28.1 \mathrm{ft}$ above the extended landing gear position. The center of mass at the initial starting condition was $6.6 \mathrm{ft}$ below the DERP. The four RCS jets were placed in a ring around the descent stage using an orthogonal quadrant of four individual thrusters for attitude control. The RCS thruster size was experimentally varied. The RCS jets were located at a $14.8 \mathrm{ft}$ radial from the centerline of the vehicle (i.e., the moment arm), approximately $7.7 \mathrm{ft}$ below the DERP.

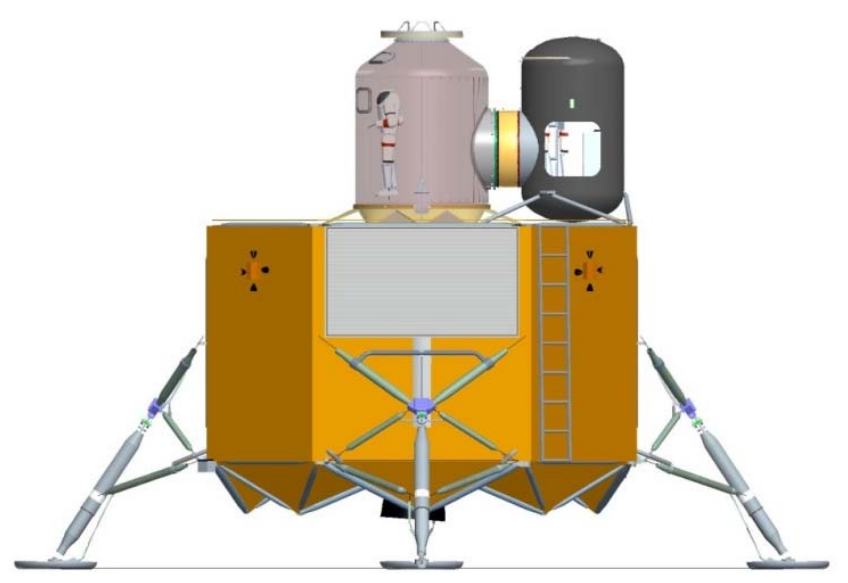

Figure 5: Simulated Lunar Landing Vehicle

\section{Control Laws}

The guidance and control laws were implemented in Simulink/Stateflow and autocoded for use in the real-time simulation shell (LaSRS++).

RCAH control laws (in body-axis pitch, roll and yaw axes) included an RCS mixer which determined the jets to fire to provide the commanded accelerations. The rate deadband for the phase plane controller was $2.0 \mathrm{deg} / \mathrm{sec}$ and the attitude deadband was $0.5 \mathrm{deg}$.

Sixteen RCS jets were arranged in four quads, with four orthogonal jets in each quad (Figure 6). A simplified thruster mapping dedicated RCS thruster firings to each moment command. Because of the simplified logic, when simultaneous pitch and roll inputs are commanded, the control authorities are effectively halved in each axis. Various jet combination mappings were considered but rejected for simplicity of design.

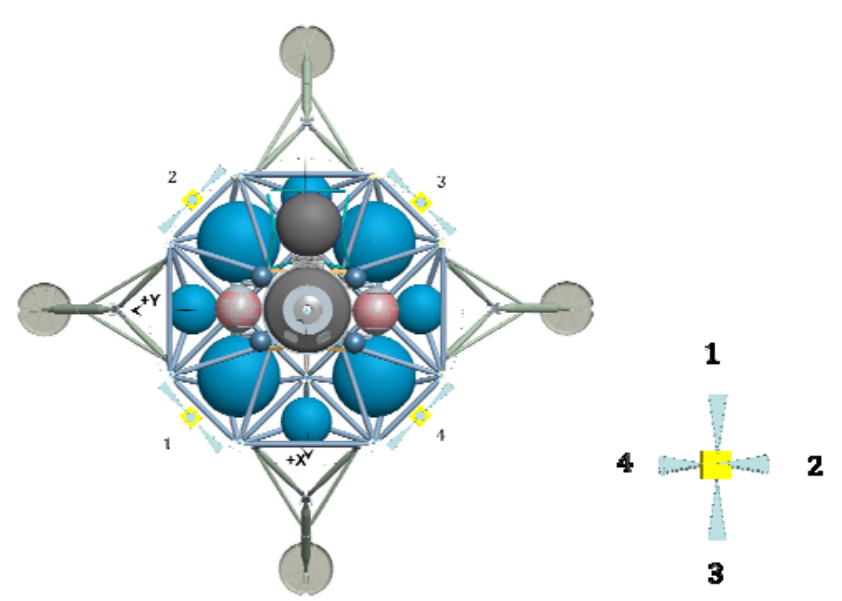

Figure 6: Descent Module (top view) RCS Locations Quads 1-4 and Jets 1-4 on each Quad

The RCS jet size was experimentally varied to create various angular acceleration control authorities.

An autothrottle was mechanized to hold a pilot-commanded vertical descent rate. Translational Hand Controller (THC) pilot inputs commanded discrete one $\mathrm{ft} / \mathrm{s}$ increments to the commanded vertical descent rate. Proportional and integral control modulated the descent engine thrust. The engine throttle response rate was not limited.

\section{Simulator}

The experiment was conducted in the fixed-base Lunar Flight Deck simulation facility at NASA Langley Research Center (LaRC). The Lunar Flight Deck used multiple projectors and a dome screen to provide a $135^{\circ}$ horizontal (H) $\times 67.5^{\circ}$ vertical (V) field-of-view. The screen was located $10.6 \mathrm{ft}$ from the DERP. The dome and projection system were biased to provide $22.5^{\circ}$ up and $45.0^{\circ}$ down viewing angle from the DERP. The multiple image generators and projectors are warped and blended to provide uniform and seamless $\sim 30$ pixels per deg resolution across the field-of-view, referenced to the DERP.

A lunar polar landing site was preferred for the evaluations but terrain data of reasonable resolution was not available. Instead, the Apollo 15 landing site was utilized because of the availability of higher resolution data and the interesting terrain features it provided. The out-the-window (OTW) lunar database was created using lunar topology and imagery data collected by the Clementine project [41]. Medium resolution data was used in the general area of the Apollo 15 landing site, approximately 500 meters per elevation post, draped with 125 meter per pixel imagery. Higher resolution data was inset in the immediate vicinity of the Apollo 15 landing site (15 meters per elevation postspacing, draped with 4 meter per pixel imagery).

In the landing area, the resolution of the OTW database was good, but not to levels approaching the real-world. The 
OTW presentation was augmented with boulder and habitat models to increase the visual density.

The evaluation pilot (EP) conducted the task in a standing position, analogous to the Apollo Lunar Module design. The crew station is shown in Figure 7. A window (20 inch $\mathrm{H} \mathrm{x}$ 14 inch V) approximated the field-of-view anticipated for a Lunar Lander vehicle. Two head-down (13.25 inch H x 10.5 inch V) displays, using 1280 x 1024 pixel resolution, provided primary flight, navigation, and systems awareness for the EP.

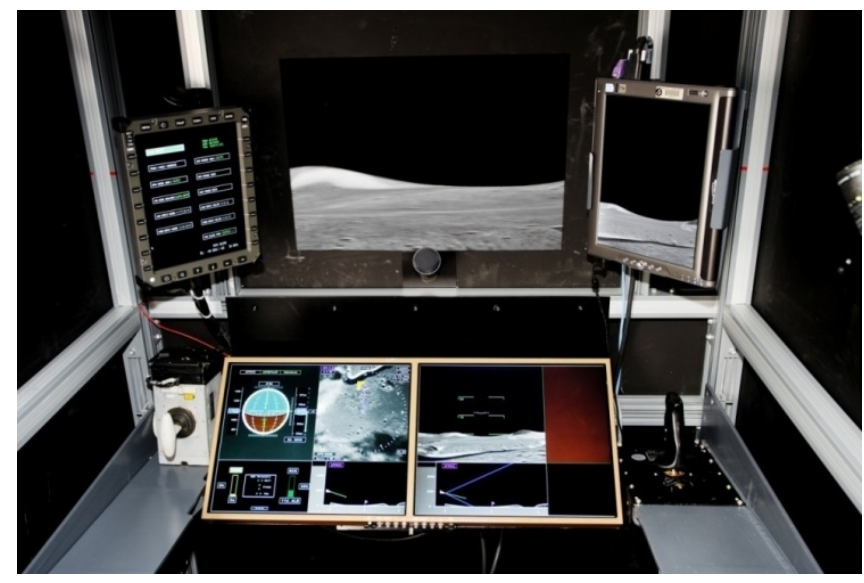

Figure 7: Lunar Landing Flight Deck

\section{Control Inceptors}

The EPs used an Apollo-vintage Rotational Hand Controller (RHC) and Translational Hand Controller (THC). The controllers were mechanical and their characteristics fixed.

The right-hand RHC provided 3-axis rotational control commands, using a base pivot for roll, palm-pivot for pitch, and twist-pivot for yaw. The mechanical characteristics of the RHC provided +/- 27.5 deg total deflection in roll using a maximum force of $3.5 \mathrm{lb}$ applied at the roll pivot point (five inches above the roll rotation point, approximately mid-grip). There was approximately $0.5 \mathrm{lb}$ of hysteresis with $1.0 \mathrm{lb}$ of break-out force.

The mechanical characteristics of the RHC provided +/-15.0 deg total deflection in pitch with maximum force of $3.5 \mathrm{lb}$ applied at the pitch pivot point $(\sim 2.625$ inches above the rotation point, near top of grip). There was approximately $0.75 \mathrm{lb}$ of hysteresis with $0.25 \mathrm{lb}$ of break-out force.

A deadband function using $15 \%$ of the full-throw deflections was applied to the pitch and roll signal and scaled to create a $+/-1.0$ command signal. The scaled roll and pitch inputs $(\delta)$ were parabolically shaped to create the pitch rate and roll rate commands ( $q_{s}$ and $p_{s}$, respectively) using the equation $p_{s}, q_{s}=\delta *(1-$ Shape $)+$ Shape $* \delta *$ $|\delta|$ where the term Shape was equal to 0.90 . The shaping function appropriately tailored the response sensitivity for the sidestick controller.
The resulting parabolic shaping mimics that used in Apollo. The shaped roll and pitch inputs were multiplied by 12 $\mathrm{deg} / \mathrm{sec}$ to create the pilot commanded roll and pitch $\mathrm{RCAH}$ control law inputs.

The left-hand THC was provisioned for 3-axis translational control commands but only up/down vertical commands were active. Up/down pilot inputs of the THC were converted into vertical descent rate command increments. Each discrete THC input would increment the value of the commanded descent rate by one $\mathrm{ft} / \mathrm{sec}$.

Aural call-outs of the altitude above the terrain (extended gear height) were provided during the landing phase in $10 \mathrm{ft}$ increments starting at $150 \mathrm{ft}$ and continuing until touchdown.

\section{Head-Down Displays}

The two-color head-down displays showed four primary display formats: a) Attitude Direction Indicator (ADI); b) Navigation Display (ND); c) Vertical Situation Display (VSD); and Auxiliary Display.

The ADI (Fig. 8) served as the primary flight display. The ADI showed lunar attitude reference using a roll/pitch/yaw "eight-ball." The ADI included digital readouts of ground speed (in knots), altitude (in $\mathrm{ft}$, height above the landing zone), radar altitude (in $\mathrm{ft}$, height terrain below extended gear position), and vertical descent rate (in $\mathrm{ft} / \mathrm{sec}$ ). On the vertical descent rate display, a magenta circle indicated the guidance-commanded descent rate. Yellow pitch, roll, and yaw "flight director" needles were also displayed depending upon the experimental condition. The needles provided "flyto" pitch, roll, and yaw attitude guidance to fly the trajectories to landing. Additional, less-critical status mode information was shown in periphery.

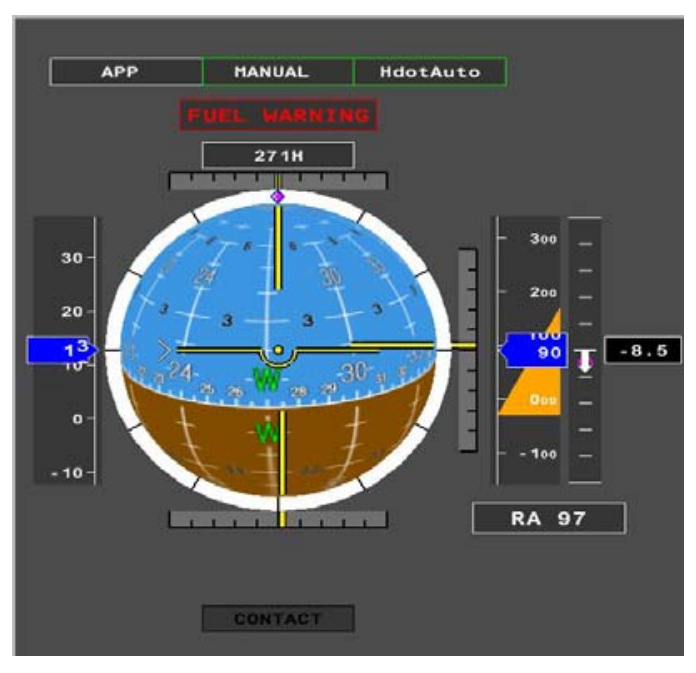

Figure 8: ADI

The ND provided a top-down, "God's eye" view of ownship position and the planned landing zone (Fig. 9). The ND was 
always drawn with ownship in the center, heading up, and the range scale automatically adjusted to keep the landing zone on the display. Synthetic imagery was used in the background. The ND transitioned from a flight-mode to a hover mode once the ground speed was less than 38 knots.

- In the flight-mode, the landing zone was depicted by a magenta-colored hexagon symbol.

- In hover mode, the landing zone was depicted by two octagons. The octagons were sized to accurately represent the size of the desired and adequate landing performance standards. In addition, digital display of the body-axis forward and side velocities were presented with a graphical representation of this same information, indicated by a white line and cross symbol emanating from the ownship position.

- In the hover mode, a hover cue symbol was also displayed, depending upon the experimental condition.

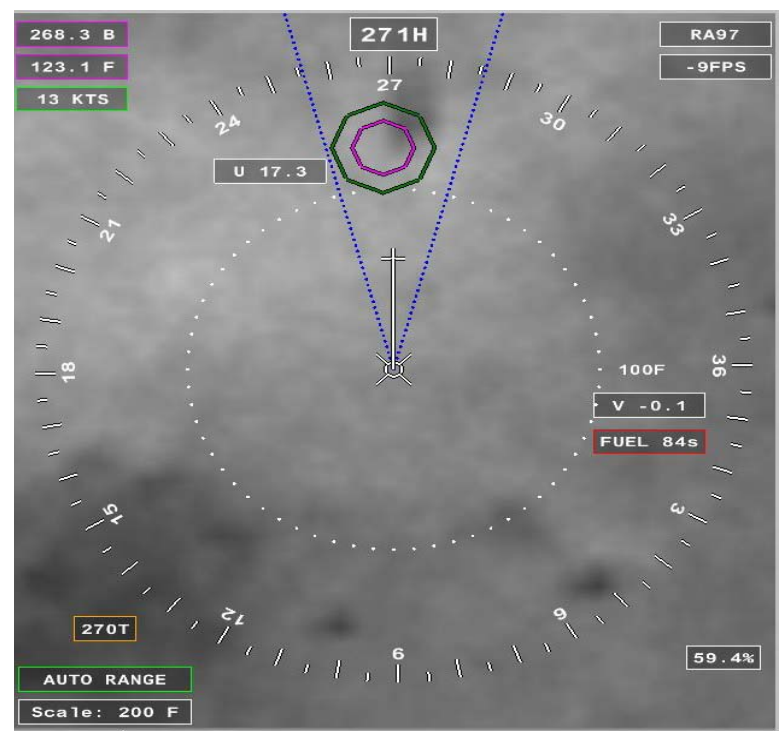

Figure 9: ND - Hover Mode

The VSD provided a profile/side view of ownship position and the landing zone. The auxiliary display provided a simulated forward looking infrared (FLIR) image of the outside world from $45^{\circ}$ to $75^{\circ}$ nose-low from the DERP. This camera view supplemented the EP's visibility below the $45^{\circ}$ cut-off of the simulated window.

\section{Command Guidance}

The ADI flight director bars were driven to provide explicit pitch, roll, and yaw command guidance to fly an approach path, transition to a vertical descent, and conduct a vertical landing. The guidance was defined in a series of phases, depending on distance from the landing site.

The command guidance used three phases:

- The approach phase used a constant deceleration profile which allowed for a near-constant pitch (deck) angle, flight path angle and thrust-to-weight ratio. The guidance provided corrections to pitch angle, roll angle and thrust level of the vehicle to correct for any deviations from the desired trajectory.

- The guidance mode switched to a hover phase at a fixed-time prior to the end of the straight-line approach phase trajectory. In this phase, pitch angle, roll angle and thrust level commands would bring the vehicle to a hover over the landing target at $\sim 100 \mathrm{ft}$ height.

- The final descent phase was initiated once the pitch, roll, velocity and horizontal position of the vehicle was within parameters over the designated landing area.

\section{Hover Cue Guidance}

An alternative form of flight guidance was mechanized for experimental variation as a possibly simpler means of enabling lunar landings and tailored toward manual control considerations. In this case, the guidance was in the form of a hover cue. The hover cue is part of an integrated symbology set, including the ownship position symbol, velocity vector, and conformal landing zone designator.

The hover cue was mechanized as a "fly-to" symbology element where the positioning and dynamics of the cue provided manual control guidance for the pilot to smoothly approach a desired landing position and achieve zero horizontal velocity (i.e., a hover condition). The pilot's task is to use the pitch and roll inceptor to place the hover cue and hold its position over the desired landing site (i.e., "put the ball in the octagon").

The hover cue closely follows from rotorcraft work [42] with adaptation for a non-atmospheric flying vehicle as described in the following. The cue is, in essence, a flight director. The motivation for this "guidance" element is that, if successful, a hover cue would be ideally suited for a manually-controlled re-designated landing task, especially when coupled with a head-up display or head-worn display projecting this cue against conformal imagery or the actual lunar terrain. In these cases, the hover cue would be controlled by the pilot, superimposed on a pilot-selected landing site; the hover cue "guidance" provides a simple means of achieving a hover over a pilot-designated point.

For this work, the conformal landing zone designator was the desired touchdown/landing position. The velocity vector provided a graphical depiction of the horizontal velocity (digital readouts of forward and side velocity were also provided). The hover cue was shown on either the ND or on a Head-Worn Display (HWD) [41].

Ownship position was fixed in the center of the display and automatic range settings were applied to keep the landing zone at a reasonable range scale on the displays.

Earth-bound vehicle applications of the hover cue guidance have been implemented, but to the authors' knowledge, this was the first lunar lander application. 
In the design of the hover cue dynamics, it has been assumed that three coincident real-axis roots between aircraft velocity and stick position produced desirable dynamics [42]. The positioning of the hover cue followed this assumption where the pilot applies compensation to control the hover cue in a position (x) closure task (Figure 10).

With this assumption, the longitudinal position of the hover cue, $A_{x}$ is derived. The lateral position, $A_{y}$, was directly analogous, but not shown here.

The longitudinal position was computed from:

$$
A_{x}=K_{\dot{x}} \frac{\left(s+\omega_{0}\right)^{3}}{\omega_{0}^{3}} \dot{x}
$$

where $K_{\dot{x}}$ is a display gain, $\mathrm{deg} / \mathrm{ft} / \mathrm{sec}$. $\omega_{o}$ is a bandwidth parameter, $\mathrm{rad} / \mathrm{sec}$ $\dot{x}$ is the body-axis forward velocity, $\mathrm{ft} / \mathrm{sec}$

This equation is algebraically expanded to yield:

$$
A_{x}=\frac{K_{\dot{x}}}{\omega_{0}^{3}} \ddot{x} s^{2}+3 \frac{K_{\dot{x}}}{\omega_{0}^{2}} \ddot{x} s+3 \frac{K_{\dot{x}}}{\omega_{o}} \ddot{x}+K_{\dot{x}} \dot{x}
$$

The term, $K_{\dot{x}} \dot{x}$ positions the reference for the hover cue at the same location as the velocity vector, where $K_{\dot{x}}=K u$. in Figure 10. For our lunar lander application, a small angle approximation was invoked so $\ddot{x}=-T / m \theta$ where $\mathrm{T}$ is the vehicle thrust, $\mathrm{m}$ is the mass, and $\theta$ is the pitch attitude. Thrust and mass were real-time variables in the guidance calculation. It then follows that $\ddot{x} s=-T / m q$, where $\mathrm{q}$ is the vehicle pitch rate.

The first term, $\ddot{x} s^{2}$ was derived using the RHC stick position $(\delta)$. The vehicle control laws were RCAH-type, but manifested as a discrete, phase-plane controller without aerodynamic damping effects. Using a loose approximation for an RCAH control law, ${ }^{q} / \delta=K_{R C A H} /(\tau s+1)$, the $\ddot{x} s^{2}$ term was approximated by $(-T / m) K_{R C A H}(s /(\tau s+1)) \delta$. By this assumption, the hover cue effectively uses a washed-out RHC input $(\delta)$ where the time constant, $\tau$, is dependent upon the responsiveness of the pitch rate controller. The time constant $(\tau)$ was selected to approximate the pitch rate response of the phase-plane controllers and the gain, $\mathrm{K}_{\mathrm{RCAH}}$ was equal to the maximum, full stick deflection rate command $(12 \mathrm{deg} / \mathrm{sec})$. Since the angular acceleration was experimentally varied, the selected values for $\tau$ (shown in Table 2) were varied accordingly. These $\tau$ values were defined by the approximate time to reach $63 \%$ of the spacecraft's rate response for a full-stick input command.
Table 2

Values for RCAH Time Constant / Hover Cue

\begin{tabular}{|c|c|c|}
\hline RCS Jet Size & Control Power & $\boldsymbol{\tau}$ \\
\hline \hline $68 \mathrm{lbf}$ & $1.1 \mathrm{deg} / \mathrm{sec}^{2}$ & $7.0 \mathrm{sec}$ \\
\hline $100 \mathrm{lbf}$ & $1.6 \mathrm{deg} / \mathrm{sec}^{2}$ & $5.0 \mathrm{sec}$ \\
\hline $180 \mathrm{lbf}$ & $2.9 \mathrm{deg} / \mathrm{sec}^{2}$ & $2.75 \mathrm{sec}$ \\
\hline $270 \mathrm{lbf}$ & $4.3 \mathrm{deg} / \mathrm{sec}^{2}$ & $1.75 \mathrm{sec}$ \\
\hline $540 \mathrm{lbf}$ & $8.6 \mathrm{deg} / \mathrm{sec}^{2}$ & $1.0 \mathrm{sec}$ \\
\hline
\end{tabular}

Navigation Display

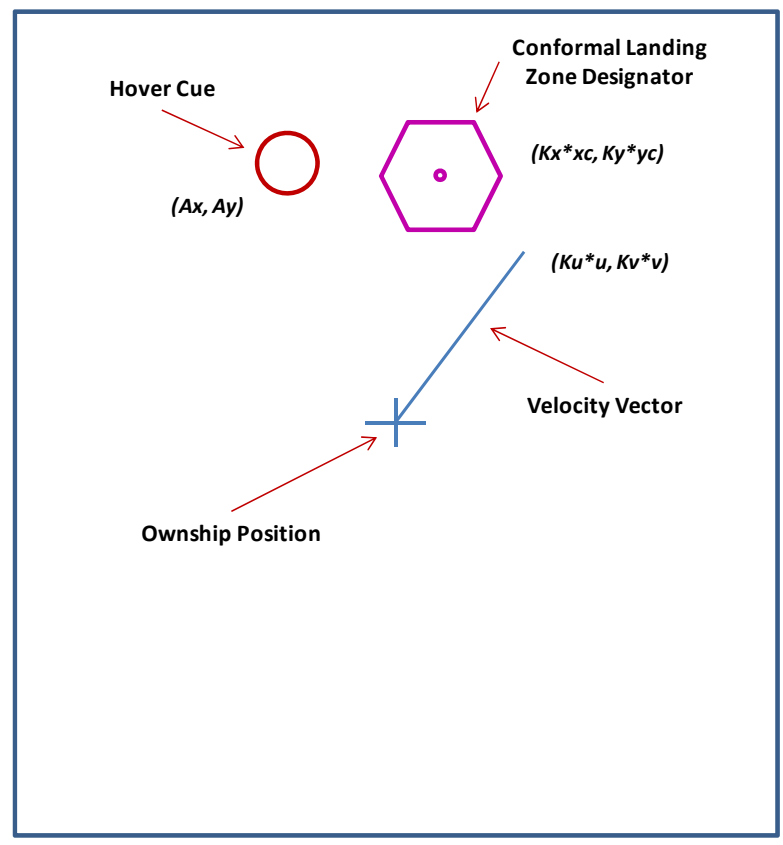

Figure 10: Illustration of Hover Symbology

The sensitivity or scaling of the hover cue critically influences its utility and usability. The selections and rationale were as follows:

- The ND range was automatically adjusted to keep the landing zone conformally on the screen. The visual angle subtended by the ND was approximately $20 \mathrm{deg}$. Therefore, the display unit scaling, $K_{x}$, was equal to 20 $\mathrm{deg} / \mathrm{ND}_{\text {range }}$, where $\mathrm{ND}_{\text {range }}$ was the automatically set range scale in $\mathrm{ft}$. The minimum navigation scale range $\left(\mathrm{ND}_{\text {range }}\right)$ was $200 \mathrm{ft}$.

- Pre-test experimentation indicated that a bandwidth selection $\left(\omega_{0}\right)$ of $0.5 \mathrm{rad} / \mathrm{sec}$ was a reasonable selection considering the piloting demands for this task and the vehicle dynamics being considered as "representative" for a lunar landing mission.

- As detailed in [42], the relationship between the velocity scaling and the display scaling (in addition of the bandwidth parameter) effectively specify the speed 
of the position loop closure response. For the selected bandwidth, root locus calculations for the assumed loop closure task dictated that a well-damped loop gain, $K_{x} /_{K_{\dot{x}}}$ should be 0.065 (which provided a damping ratio of 0.85$)$. The velocity display scaling $K_{\dot{x}}$ falls out.

Smoothing was applied to the input signals to temper (somewhat) the jerkiness of the symbol movement due to the discrete nature of the RCS firings. First-order, low-pass filters were applied to the attitudes, and attitude rates with time constants of $0.2 \mathrm{sec}$ and $0.1 \mathrm{sec}$, respectively. Firstorder, low-pass filters were also applied to the RHC inputs to eliminate high-frequency noise in the signal, using a time constant of $0.2 \mathrm{sec}$.

\section{Experiment}

The primary experimental goal was to evaluate the interaction of controls and displays on the handling qualities of a lunar landing vehicle. Variations in approach trajectory were experimentally tested because they interact with fuel and natural vision viewability of the landing zone.

A full-factorial matrix was developed, consisting of 3 approach trajectories $(15,30$, and $45 \mathrm{deg})$, five control powers (Table 2), and 2 guidance conditions (head-down guidance on ADI and hover cue flight director). The hover cue was also evaluated as part of a "virtual HUD" concept using a HWD [41]. Due to time limitations, a subset of this matrix was identified as the primary matrix which the majority of EPs were to evaluate; the remainder of the matrix was tested as time permitted.

Each run of the experiment began $1000 \mathrm{ft}$ above the landing target. Three different approach angles were experimentally varied: $15 \mathrm{deg}$; $30 \mathrm{deg}$; and $45 \mathrm{deg}$. The initial distance uprange from the landing site was varied accordingly. The initial velocity varied as well to provide approximately the same duration of the approach from start to finish.

Evaluation Tasks_-Each run started at approximately 1000 $\mathrm{ft}$ above the landing zone elevation flying on auto-pilot following the constant deceleration trajectory profile, to a designated landing zone directly forward of the vehicle's track. This period of auto-flight provided two benefits: 1) it allowed the pilots to prepare for the next phase (manual flight); and, 2) it was representative of an operational profile, where the auto-flight system will fly to a certain altitude, but the crew will take-over manually for the final landing. This procedure was done for all Apollo flights [27] and will likely occur for other crewed missions. An additional motivation is that this auto-flight period might be representative of a re-designation period where the crew might be evaluating real-time sensor data and navigation systems data to decide if the planned landing zone is safe and appropriate or if a landing zone re-designation is necessary [29].

At $500 \mathrm{ft}$ above the touchdown zone, the auto-flight system was disconnected automatically. An aural auto-flight disconnect alert was triggered. Concurrently, the landing zone was automatically re-designated left or right by $250 \mathrm{ft}$ from its original position. The EP was then tasked to fly and land on this re-designated landing zone using either the hover cue (hereafter referred to as the "aided" condition) or explicit pitch/roll guidance (hereafter referred to as the "guided" condition).

The $250 \mathrm{ft}$ offset landing zone mimicked the scenario where a re-designated landing zone had been executed and the pilot must now fly to the new landing area. The scenario was also analogous to the offset landing task from the aeronautics domain. The $250 \mathrm{ft}$ offset was chosen to match previously conducted work $[31,38]$.

The pilot's task was to control the vehicle's trajectory, fly to a hover transition, and execute a vertical descent to land to achieve prescribed landing performance standards using either explicit guidance or a hover cue in addition to available out-the-window visual cues.

In both conditions, the desired descent rate to fly to the hover transition point, developed from the guidance concept described above, was provided. Vertical descent rate was controlled by discrete THC inputs.

The desired and adequate performance standards are shown in Table 3. These parameters only applied to the landing. At the end of each run, a "scorecard" was shown on their headdown display given them their performance against each of these standards.

Table 3

Task Performance Standards

\begin{tabular}{|l|l|l|}
\hline Parameter & $\begin{array}{l}\text { Desired } \\
\text { Performance }\end{array}$ & $\begin{array}{l}\text { Adequate } \\
\text { Performance }\end{array}$ \\
\hline \hline $\begin{array}{l}\text { Range At } \\
\text { Touchdown }\end{array}$ & $<15 \mathrm{ft}$ & $<25 \mathrm{ft}$ \\
\hline Sink Rate & $<5 \mathrm{ft} / \mathrm{sec}$ & $<7 \mathrm{ft} / \mathrm{sec}$ \\
\hline $\begin{array}{l}\text { Forward/Side } \\
\text { Velocity }\end{array}$ & $<2 \mathrm{ft} / \mathrm{sec}$ & $<4 \mathrm{ft} / \mathrm{sec}$ \\
\hline Pitch/Roll Angle & $< \pm 3 \mathrm{deg}$ & $< \pm 6 \mathrm{deg}$ \\
\hline Pitch/Roll Rate & $< \pm 3 \mathrm{deg} / \mathrm{sec}$ & $< \pm 1.5 \mathrm{ft} / \mathrm{sec}$ \\
\hline Yaw Rate & $< \pm 1.0 \mathrm{deg} / \mathrm{sec}$ & \\
\hline
\end{tabular}

No performance standards were enforced during the approach phase with the exception of a vertical descent rate performance standard. The pilots were instructed to follow the vertical descent rate guidance, but the pilots were told that if they stopped their descent, their task performance could be no better than "adequate". If they climbed, their task performance was considered "not adequate." Fuel usage (propellant consumption) was not a parameter in the task performance standards, because this test was designed as an evaluation of handling qualities. Fuel consumption, of course, is critical for a spacecraft design and it is analyzed 
post-test because of its criticality. To use it as a CooperHarper task performance standard would skew the piloting technique to minimize propellant usage. The vertical descent rate requirement was the one concession to criticality of fuel. The descent rate criteria essentially required that the vehicle was continually descending toward the landing zone. If a hover condition, or worse yet, a climb is performed, fuel consumption will be unreasonable given that this type of vehicle will undoubtedly be "fuel-critical." While a hover or climb may be technically feasible, it would have to be a last-ditch maneuver. A hover or climb essentially buys the crew more time to control the vehicle. This is a sign of poor handling qualities since the landing site is assumed to be clear of obstructions. Therefore, task performance penalties were enforced.

\section{Other Elements}

Experiment Protocol-Prior to the start of data collection, the EPs were briefed on the purpose of the experiment and flew numerous practice trials following the experiment protocol with a variety of experimental configurations until they reached an acceptable, consistent level of proficiency in the task. Upon the start of formal data collection, for each configuration, the EPs first flew one approach and landing for practice/familiarity, followed by a minimum of two runs for "data." The EP had the option for a third run if they felt that the two runs exhibited very different characteristics that potentially hampered their handling qualities assessment.

Following the tasks, the EPs assigned a HQR using the Cooper-Harper rating scale. Pilot comments were then given, generally prompted via a comment card. Finally, NASA Task Load Index (TLX) workload ratings were given.

Evaluation Pilots-Eight EPs flew this experiment, completed in 2009. All subjects had graduated as pilots from the U.S. Air Force or Navy Test Pilot Schools and were experienced in aircraft handling qualities evaluations. Needless to say, none were experienced in lunar landings. Some had considerable experience in rotary wing vehicles. Two of the EPs were current or former Astronauts.

\section{Holistic Impact of Design/HQs}

The influence - and interdependency - of manual control handling qualities and the vehicle design considerations are described using the handling qualities results.

Effect of Glideslope Variations - Piloting Task Influence By the nature of the constant deceleration approach profile, the approach phase was essentially a pitch attitude maintenance task. Very few pitch inputs were required to maintain the approach path once manual control was required. So the initial task was primarily a roll task to start tracking toward the new landing zone. The pilot had from the $500 \mathrm{ft}$ altitude point to the hover transition to correct for the lateral offset. For all glideslopes flown, the $250 \mathrm{ft}$ offset approach (simulating a landing point redesignation) was a reasonable piloting task. The flight crew had sufficient time to effect a landing.

At the hover transition point, the constant deceleration profile could create a significant pitch task. This task was most demanding for the lower glideslope angles. For instance, the $15 \mathrm{deg}$ glideslope approach used a fairly large pitch attitude $\left(\sim 20^{\circ}\right.$ pitch attitude) that had to be removed very quickly and precisely as the hover transition point was reached. If not, the vehicle would undershoot or overshoot the landing zone and then, low altitude re-corrections were necessary. In contrast, the $45 \mathrm{deg}$ glideslope approach involved very little pitch attitude change. The ground speed approaching the landing zone was considerably less. As such, the hover transition was neither as large nor did it require as high a degree of precision. The $45 \mathrm{deg}$ approach task was more of a lateral tracking task, whose duration consists of the entire approach. The $15 \mathrm{deg}$ approach task was much more demanding, involving both the lateral offset and the abrupt pitch-over near the hover transition point.

These observations were quantified by the HQRs as shown in Figure 11. The pilot rating data is plotted for the highest control power condition $\left(8.6 \mathrm{deg} / \mathrm{s}^{2}\right)$ as the task and guidance method was varied. For the shallow $15 \mathrm{deg}$ glideslope, some Level 1 and some Level 3 ratings were given. These significant rating discrepancies reflect subtle timing and piloting differences in transitioning to the hover phase can create significant performance differences. Conversely, predominately Level 1 ratings were given in the 45 deg glideslope, reflecting an easier piloting.

Apollo used more of a constant jerk profile (first derivative of acceleration) [43] with a tailored pitch-up prior to the hover transition. Apollo experience showed that a constant deceleration profile was not preferred because of the abrupt pitch change and the need for a natural vision viewing opportunity. These data show that a constant deceleration profile is do-able, especially for higher glideslopes.

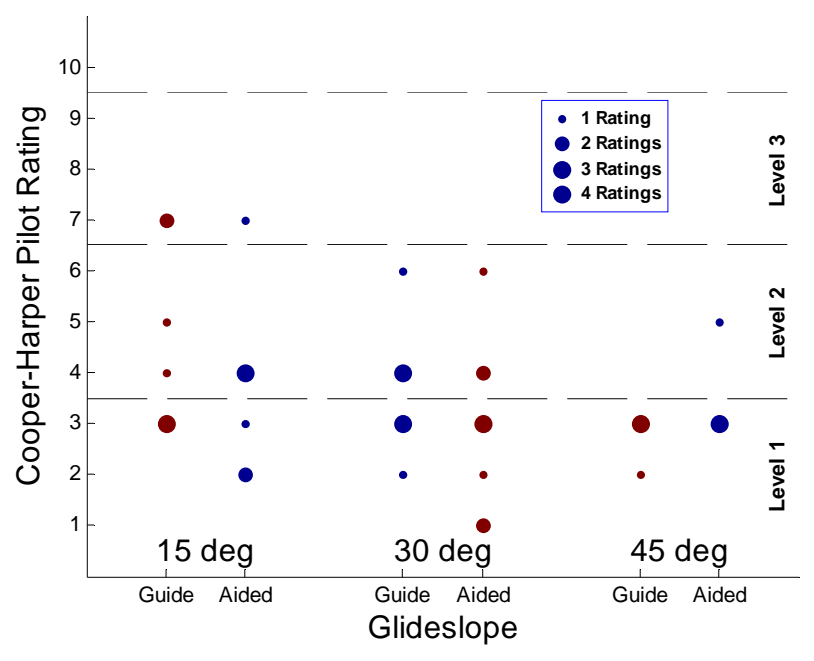

Figure 11: HQRs of Glideslope and Guidance Variation (8.6 deg/ $/ \mathrm{s}^{2}$ control power) 
Guidance Method-Two concepts for guidance were tested, Guided (using ADI needles) vs. Aided (using a hover cue on the navigation display).

The data generally showed that explicit attitude guidance was good in that it provide simple and straight-forward command information to enable the transition from the approach to a hover over the landing area. The command information provided guidance as to when and what magnitude of pitch and roll attitude changes were required to establish a hover over the landing zone. The display was unambiguous and clear and all critical flight information (attitude, guidance, speeds, and descent rate information) was in close visual proximity. Especially for low control power configurations, vehicle attitude was critical "lead" information required to keep the vehicle under control and to anticipate the size and timing of control inputs to get into the hover position.

Unfortunately, the pitch attitude change, especially for the $15 \mathrm{deg}$ approaches near the hover transition point, required close attention by the EP. It also required precision on the part of the EP to track the attitude to achieve desired performance. If neither of these conditions were met, the vehicle could significantly overshoot or undershoot generating low altitude corrections and workload on the part of the pilot to use the guidance and the ND to re-correct to the landing zone.

This control behavior is most apparent in the HQR data for the lowest control power test $\left(1.1 \mathrm{deg} / \mathrm{s}^{2}\right)$ as shown in Figure 12. Clear Level 3 handling qualities were indicated for 15 deg glideslope landing tasks using ADI guidance. As the task got easier, the impact was not as severe (15 to $45 \mathrm{deg}$ glideslope).

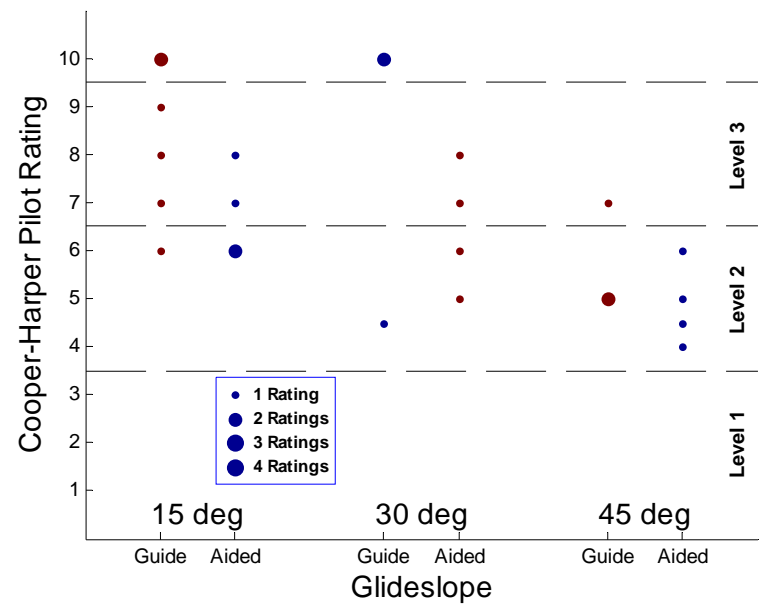

Figure 12: HQRs of Glideslope and Guidance Variation (1.1 deg/s ${ }^{2}$ control power)

In general, the EPs preferred the aided condition, using the hover cue. The cue took some training (for those that didn't have experience with it), but after training, the cue provided some captures of the landing zone.
The pilot rating and comment data also indicated areas where the hover cue needs to be improved as well. The discrete nature of the control law induced some substantial "jumpiness" in the position of the symbol. Throttle changes caused by descent rate control inputs and RCS deadband firings were most problematic. Pilots often learned to "filter" this out, but they desired more predictable response behavior. Also, pilots could get behind the hover cue and enter into overcontrol / pilot-induced oscillations for the low control power configurations. Vehicle attitude still needed to be monitored and this information was not in immediate spatial proximity. Methods to ameliorate these characteristics were identified but not implemented at this time. The aided condition was clearly preferred especially since it broke the criticality of timing in successfully completing the task. The pilots were more directly in control of the hover transition task.

Head-Down vs. Head-Up Information-The various trajectories, in addition to piloting task differences, modulated the amount of time that the EPs could use the OTW visual cues for the task.

- The task was flown almost completely head-down. All the information required to conduct the task was available on the ADI and ND.

- However, almost all EPs noted the importance out-thewindow visual cues for verification and validation of the head-down information. This was not part of the test but it should be evaluated in the future. For this test, the navigation solution was perfect (no errors) so the ND presentation was a completely faithful representation of the outside landing zone.

- The OTW visual cues were insufficient alone for the EPs, in general, to control the vehicle - at least to the degree that they could in rotary wing aircraft. Higher resolution terrain data is required to test and possibly, achieve this capability.

- Head-up information, conformal information was desired/preferred. The ability to use the SV/EV information and out-the-window was expressed.

- It was also noted by the astronauts that the landing task was going to be a "crew effort." The out-the-window visual cues may not be critical for the commander (i.e., pilot-flying), because they will be part of the crew's tasking, where the pilot (i.e., pilot-not-flying), might visually designate the landing zone and verify/validate the navigation position accuracy.

The HWD showed significant potential in providing headup information while simultaneously showing hover cue (aided) guidance [41]. Those with previous familiarity with the hover cue (e.g. helicopter pilots) especially showed proficiency using this combination. The combination of $\mathrm{SV} / \mathrm{EV}$ information, head-up conformality, and appropriate crew tasking suggest that a long pitch-up maneuver for natural vision acquisition of the landing zone will not likely be required. 
Effect of Control Power-The data - the pilot ratings and comments - clearly indicate that increasing control power produces better handling qualities. For the Apollo-type configurations (2-jet and 4-jet Apollo RCS with 4.3 and 8.6 $\mathrm{deg} / \mathrm{s}^{2}$ angular acceleration), Level 1 ratings were generally given. On some evaluations, some improvement was still warranted with the higher control power configurations. These poorer ratings were due primarily from display deficiencies where improvements were desired.

Control powers at $1.6 \mathrm{deg} / \mathrm{s}^{2}$ and below are borderline Level 2-3 or Level 3. Even though desired performance may be achievable with these configurations, and some "good" Level 2 ratings were given, cliff-like characteristics are apparent in these configurations. If the EP fell behind the task, made an inadvertent input, or committed a control reversal, they could find themselves struggling to get back to the landing zone. Pilot ratings of 8,9 , and 10 were indicative of these conditions.

Approach Phase Piloting Task Influence-Stringent approach performance criteria were not in effect with the exception of the "don't hover," "don't climb" vertical descent rate requirement. This procedure may have allowed some of the "less than desirable" configurations to achieve "reasonable" landing performance which may have biased the ratings toward better ratings - the EPs were able to solve the conundrum presented by these sluggish configurations.

The EPs learned that THC control inputs could modulate the amount of time available to them to complete the approach and landing. If handling issues became apparent, they could use the THC to reduce their rate of descent, in essence, buying them more time to sort out the horizontal positioning control problem. In many cases, desired landing performance was achievable, even though the approaches were far from optimal. However, these performance differences were evident in the fuel usage. Better handling configurations used less fuel.

More work is needed in defining approach standards for the task. It may be necessary and appropriate to establish approach corridors and approach speeds. The approach standards might mimic a Landing Signal Officer, where an unstabilized or botched approach might warrant a "waveoff' (i.e., trigger an abort) to avoid the possibility of damage to an existing lunar habitat.

\section{HANDling QUALITIES FOR AUTOMATION}

Often, the importance of handling qualities is dismissed under the premise that the task/mission objective will be met using automated control. In fact, handling qualities or, at least, the principles of the pilot-vehicle dynamic systems analysis are critically important during automatic control.

Human-automation interface requirements flow from "manual control" handling qualities. Handling qualities are the design and evaluation of the pilot-vehicle dynamic system (Figure 1); the only fundamental difference between "manual control" and "automated control" is the physical process of activating the controller (i.e., whether it is a human or automation system at the controls). The system performance and workload (i.e., handling qualities) during this operation are still critically important.

\section{Human-Centered Automation}

History has shown that the best automation designs are human-centered. They are designed understanding the human needs and limitations in monitoring, intervention, and adaptation with automation.

Human-centered automation design principles are many and varied (e.g., see [44]). Three key principles for humanautomation interaction are directly related to the handling qualities process and must be addressed:

1) The automation must be observable by its human operator (i.e., the human operator is appropriately informed).

2) The current and near-term future behaviors of the automation must be comprehensible, understood and predictable by the human operator.

3) The automation must be contextually appropriate for its application, designed to complement the human operator, and not automated just because it is possible.

These human-automation interaction issues are mirrored in the lessons-learned from Apollo and their use of automated entry guidance and control [45]:

- "Guidance logic must be simple... the more complicated the guidance logic, the more difficult the guidance is to monitor during the mission. The monitoring difficulty complicates the development of the monitoring procedures and increased the time required for flight-crew training."

- "The guidance logic should be compatible with a backup or an alternate trajectory control procedures. That is, once an anomaly is detected in the trajectory control of the primary guidance system, an alternative technique must be available that will allow satisfactory trajectory control to be implemented so that the spacecraft will land near the originally selected target."

- "The interaction between guidance system performance and attitude control system performance must be recognized. Realistic attitude control system response requirements must be established, and guidance-logic design must minimize the need for rapid response."

\section{HQ Evaluations For Human-Centered Automation}

The handling qualities of automated tasks (i.e., humanautomation interface requirements) should be evaluated in three ways: 
1) Pilots should conduct handling qualities of all tasks to be flown by the automation. This is not to imply that these tasks could or should be manually flown. But by conducting these evaluations, the pilot gains an appreciation of what the automation must do to successfully control the vehicle. This knowledge is critical for understanding the behavior of the automation and what the pilot must do in the event (likely or unlikely) that they need or want to intervene or take-over. This task also defines what information (e.g., out-the-window visual cues or displays) are needed by the human to monitor, control, or interact with the automation.

2) Classic handling qualities evaluations must also be conducted in scenarios where, during the conduct of automated tasks, the pilot takes control of the vehicle and completes the task or temporarily intervenes and then re-engages the automation. This task evaluates the ability of the crew to interrupt the automation and the potential for upsets or discontinuities in the automation during this process. It also demonstrates the pilot's comprehension and understanding of the automation.

3) Finally, handling qualities evaluations must be conducted in scenarios where, during the conduct of automated tasks, the automation unexpectedly fails (passively or actively) and the pilot must intervene or take control of the vehicle and complete the task.

There has yet to be realized an automation design or implementation which is fool-proof and perfect. Adaptive automation is a promising, yet immature, technology. Manual control of spacecraft is now and will be for the foreseeable future desired and/or required to "allow the crew to effectively control the spacecraft when necessary for mission completion or to prevent a catastrophic event" [2]. A human-centered automation design, using "handling qualities" principles, ensures that the greatest adaptive controller ever designed - the human - can intervene, adapt, and overcome as necessary in the event that the automation is not successful.

\section{CONCLUding REMARKS}

A research, development, test, and evaluation process was put into effect to identify, understand, and interpret the engineering and human factors principles which govern the pilot-vehicle dynamic system as they pertain to space exploration missions and tasks. Toward this objective, piloted simulations were conducted at the NASA Langley Research Center and Ames Research Center for earth-orbit proximity operations and docking and lunar landing.

These works provide broad guidelines for the design of spacecraft to exhibit good handling characteristics. In particular, this work demonstrates how handling qualities include much more than just stability and control characteristics of a spacecraft or aircraft. Handling qualities include the motion, visual and aural cues of the vehicle response as the pilot performs the required operation or task.

The handling qualities implications of design decisions are demonstrated using these pilot-in-the-loop evaluations of docking operations and lunar landings. A general trend, noted in both proximity operations and docking and lunar landing, is that superior handling qualities generally results in lower fuel expenditure during the task. Data to support control and display requirements are given based on task performance and workload.

The importance of handling qualities is sometimes dismissed under the premise that the task/mission objectives will be met using automated control. It is argued that human-automation interface requirements flow from "manual control" handling qualities. Therefore, handling qualities are still critically important and these principles should be closed adhered to.

\section{REFERENCES}

[1] Cooper, G.E., and Harper Jr., R.P.: "Use of Pilot Rating in the Evaluation of Aircraft Handling Qualities." NASA TN D-5153, April 1969.

[2] Bailey, R.E., Jackson, E.B., Bilimoria, K., Mueller, E., Frost, C., and Alderete, T.: "Cooper-Harper Experience Report for Spacecraft Handling Qualities Applications," NASA Langley Research Center, Hampton, VA, NASA/TM-2009-215767, May 2009.

[3] National Aeronautics and Space Administration: "Human-Rating Requirements for Space Systems." NASA Procedural Requirements (NPR) 8705.2B, May 06, 2008.

[4] Harper, R.P, Jr. and Cooper, G.E.: "Handling Qualities and Pilot Evaluation." AIAA Journal of Guidance, Control, and Dynamics, Vol. 9, September-October 1986, pp. 515-529.

[5] Young, L.R.: "On Adaptive Manual Controls." IEEE Transactions on Man-Machine Systems, Vol. 10 No. 4, pp. 292-331.

[6] Riley, D.R., Jaquet, B.M., Bardusch, R.E., and Deal, P.L." "A Study of Gemini-Agena Docking Using a Fixed-Base Simulator Employing a Closed-Circuit Television System.” NASA TN D-3112, 1965.

[7] Riley, D.R., Jaquet, B.M., and Cobb, J.B.: "Effect of Target Angular Oscillations on Pilot-Controlled Gemini-Agena Docking.” NASA TN D-3403, 1966.

[8] Long, E.R., Jr., Pennington, J.E., and Deal, P.L.: "Remote Pilot-Controlled Docking With Television." NASA TN D-3044, October 1965.

[9] Pennington, J.E., Hatch, H.G., Jr., Long, E.R., and Cobb, J.B.: "Visual Aspects of a Full-Size Pilot- 
Controlled Simulation of the Gemini-Agena Docking." NASA TN D-2632, 1965.

[10] Jaquet, B.M. and Riley, D.R.: "An Evaluation of Gemini Hand Controllers and Instruments for Docking." NASA TM X-1066, 1965.

[11] Riley, D.R., Jaquet, B.M., Pennington, J.E., and Brissenden, R.F.: "Comparison of Results of Two Simulations Employing Full-Size Visual Cues for Pilot-Controlled Gemini-Agena Docking." NASA TN D-3687, Nov. 1966.

[12] Hatch, H.G., Jr., Riley, D.R., and Cobb, J.B.: "Simulating Gemini-Agena Docking." Astronautics and Aeronautics, Vol. 2, No. 11, Nov. 1964, pp. 74-81.

[13] Cheatham, D.C. and Hackler, C.T.: "Handling Qualities For Pilot Control Of Apollo Lunar-Landing Spacecraft." Journal Of Spacecraft And Rockets, Vol. 3, No. 5, 1966, pp. 632-638.

[14] Stengel, R.F.: "Manual Attitude Control Of The Lunar Module." Journal of Spacecraft and Rockets, Vol. 7, No. 8, 1970, pp. 941-948.

[15] Goodman, J.L.: "History of Space Shuttle Rendezvous and Proximity Operations." Journal of Spacecraft and Rockets, Vol. 43, No. 5, September-October 2006.

[16] Stephens, J-P, Vos, G.A., Bilimoria, K.D., Mueller, E.R., Brazzel, J., and Spehar, P.: "Orion Handling Qualities During ISS Proximity Operations and Docking." AIAA Guidance, Navigation, and Control Conference, AIAA Paper 2011-6261. 8-11 August 2011, Portland, Oregon.

[17] Bailey, R.E., Jackson, E.B., Goodrich, K.H., Ragsdale, W.A., Neuhaus, J., and Barnes, J.: "Investigation of Reaction Control System Design on Spacecraft Handling Qualities for Docking." AIAA Journal of Guidance, Control, and Dynamics, Vol. 32, No. 6, Nov-Dec 2009, pp. 1723-1735.

[18] Mueller, E., Bilimoria, K., and Frost, C.: "Dynamic Coupling and Control Response Effects on Spacecraft Handling Qualities During Docking." Journal of Spacecraft and Rockets. Vol. 46, No. 6, pp. 12881297. 2009.

[19] American Institute for Aeronautics and Astronautics: "Guide for the Serviceable Spacecraft Grasping/Berthing/Docking Interfaces." AIAA G-0561992, American Institute for Aeronautics and Astronautics, New York, New York, 1992.

[20] Bilimoria, K., Mueller, E., and Frost, C.: "Handling Qualities Evaluation of Piloting Tools for Spacecraft Docking in Earth Orbit." Journal of Spacecraft and Rockets. Vol. 48, No. 5, September-October 2011.
[21] Jackson, E.B., Goodrich, K.H., Bailey, R.E., Barnes, J.R., Ragsdale, W.A., and Neuhaus, J.R.: "Investigation of Control System and Display Variations on Spacecraft Handling Qualities for Docking with Stationary and Rotating Targets." NASA Langley Research Center, Hampton, VA, NASA/TM2010-216194. Feb 2010.

[22] Hackler, C.T., Brickel, J.R., Smith, H.E., and Cheatham, D.C.: "Lunar Module Pilot Control Considerations." NASA TN D-4131, February 1968.

[23] Mindell, D.A.: "Digital Apollo: Human and Machine in Spaceflight." The MIT Press, Cambridge, MA, 2008.

[24] Major, L.M, Brady, T.M., and Paschall II, S.C.: "Apollo Looking Forward: Crew Task Challenges." Paper presented at the 2009 IEEE Aerospace Conference, 7-14 March 2009.

[25] Engle, M.: "Operational Considerations for Manned Lunar Landing Missions - Lessons Learned From Apollo." Paper presented at the Space 2004 Conference and Exhibit, AIAA Paper No. 2004-6081, San Diego, California, 28-30 September 2004.

[26] Cohen, M.M.: "From Apollo LM to Altair: Design, Environments, Infrastructure, Missions, and Operations." Paper presented at AIAA SPACE 2009 Conference \& Exposition, AIAA Paper No. 20096404, Pasadena, California, 14-17 September 2009.

[27] Major, L.M., Brady, T.M., and Paschall II, S.C.: "Apollo Looking Forward: Crew Task Challenges." Paper presented at the 2009 IEEE Aerospace Conference, Big Sky, MT, 7-14 March 2009.

[28] Prinzel II, L.J., Kramer, L.J., Norman, R.M., Arthur III, J.J., Williams, S.P., Shelton, K.J., and Bailey, R. E.: "Synthetic and Enhanced Vision System for Altair Lunar Lander." Paper presented at the 15th International Symposium on Aviation Psychology, Dayton, OH, 27-30 April 2009.

[29] Hirsh, R.L., Chua, Z.K., Heino, T.A., Strahan, A., Major, L., and Duda, K.: "Developing a prototype ALHAT Human System Interface for landing." Paper presented at the 2011 IEEE Aerospace Conference, Big Sky, MT, 5-12 March 2011.

[30] Bailey, R.E., Kramer, L.J., and Prinzel II, L.J.: "Fusion of Synthetic and Enhanced Vision For All-Weather Commercial Aviation Operations." In NATO Human Factors and Medicine Symposium on Human Factors and Medical Aspects of Day/Night All Weather Operations: Current Issues and Future Challenges. Neuilly-sur-Seine, France: NATO RTO, April 2007, pp. 11-1-11-18. 
[31] Mueller, E., Bilimoria, K.D., and Frost, C.: "Effects of Control Power and Inceptor Sensitivity on Lunar Lander Handling Qualities." Paper presented at the AIAA SPACE 2009 Conference \& Exposition, AIAA Paper 2009-6407, Pasadena, CA, 14-17 September 2009.

[32] Duda, K.R., Johnson, M.C., and Fill, T.J.: "Design and Analysis of Lunar Lander Manual Control Modes." Paper presented at the 2009 IEEE Aerospace Conference, 7-14 March 2009.

[33] Peters, W.H. and Cox, K.J.: "Apollo Experience Report Guidance And Control Systems - Digital Autopilot Design Development." NASA TN D-7289, June 1973.

[34] Cooke, A.K.: "Rotary-Wing Control and Handling Qualities." Encyclopedia of Aerospace Engineering, John Wiley and Sons, Inc

[35] Cooper, G. E.: "Understanding and Interpreting Pilot Opinion." Aeronautical Engineering Review, Vol. 16, No. 3, March 1957, pp. 47-51.

[36] Jarvis, C.R.: "Flight-Test Evaluation of an On-Off Rate Command Attitude Control System of a Manned Lunar-Landing Research Vehicle." NASA TN D-3903, April 1967.

[37] Slayton, D.K., Stafford, T.P., Armstrong, N.A., Collins, M., and Cooper, L.G.: "Apollo: Past, Present, and Future." Paper presented at The Society of Experimental Test Pilots $13^{\text {th }}$ Symposium, Beverly Hills, CA, 25-27 September 1969,

[38] Bilimoria, K.D.: "Effects of Control Power and Guidance Cues on Lunar Lander Handling Qualities." Paper presented at the AIAA SPACE 2008 Conference and Exposition, AIAA Paper 2008-7799, San Diego, California, 9-11 September, 2008

[39] Cohanim, B.E., Fill, T.J., Paschall II, S., Major, L.M., and Brady, T.: "Approach Phase $\triangle \mathrm{V}$ Considerations for Lunar Landing." 2009 IEEE Aerospace Conference, 7-14 March 2009, pp 1-11.

[40] Leslie, R., Geyer, D., Cunningham, K., Madden, M.F., Kenny, P.S., and Glaab, P.: "LaSRS++: An ObjectOriented Framework for Real-Time Simulation of Aircraft." AIAA Modeling and Simulation Technologies Conference, AIAA Paper 98-4529, August 1998, Boston, MA.

[41] Arthur, III, J.J., Bailey, R.E., Jackson, E.B., Barnes, J.R., Williams, S.P., and Kramer, L.J.: "Part-task simulation of synthetic and enhanced vision concepts for lunar landing." Paper presented at 2010 Synthetic and Enhanced Vision, SPIE Defense, Sensing and
Security International Symposium, Orlando, FL, April 2010.

[42] Schroeder, J.A. and Merrick, V.K.: "Control and Display Combinations for Blind Vertical Landings." Journal of Guidance, Control, and Dynamics, Vol. 15, No. 3, May-June 1992, pp. 751-760.

[43] Bennett, F.V.: "Apollo Experience Report - Mission Planning for Lunar Module Descent and Ascent." NASA TN D-6846. June 1972.

[44] Billings, C.E.: "Aviation Automation: The Search For A Human-Centered Approach." Lawrence Erlbaum Associates, Publishers. 1997 Mahwah, New Jersey.

[45] Graves, C.A. and Harpold, J.C.: “Apollo Experience Report - Mission Planning for Apollo Entry." NASA TN D-6725. March 1972.

\section{ACKNOWLEDGEMENTS}

This work was made possible only by the contributions of many individuals in addition to the author's. The contributions of Mr. Ken Goodrich (NASA LaRC), Mr. James Barnes (ARINC), Mr. Jason Neuhaus (NASA LaRC), and $\mathrm{Mr}$. Al Ragsdale (Unisys, retired) were especially critical to the success of these works. In addition, the assistance of the Simulation Development and Analysis Branch at NASA Langley, led by Ms. Victoria Chung, was also gratefully appreciated.

\section{BIOGRAPHIES}

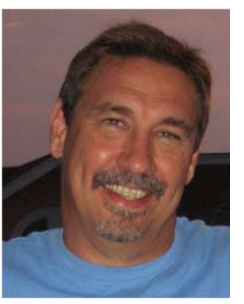

Randall Bailey received a B.S. in Aerospace Engineering from the University of Virginia and an M.S. in Mechanical Engineering from the State University of New York at Buffalo. He has been with the NASA Langley Research Center for more than 10 years. He is the technical team lead for flight deck interface technology in the Crew Systems and Aviation Operations branch. Prior to joining NASA, Mr. Bailey worked at the Calspan Corporation serving as the Technical Director for the Flight Research Department.

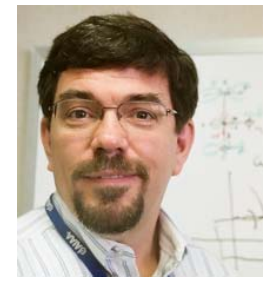

Bruce Jackson received a MS in Aeronautics and Astronautics from Stanford University in 1988. He has been a senior research engineer with NASA Langley's Dynamic Systems and Control Branch for 22 years concentrating on simulation, modeling, control design and flying qualities research; previously he worked at the Manned Flight Simulator Facility at the U.S. Navy's Naval Air Test Center in Patuxent River, MD. 


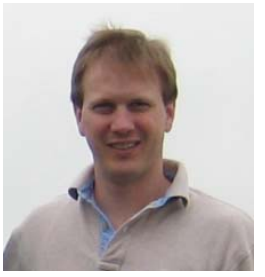

Trey Arthur received a BS in Aerospace Engineering from the North Carolina State University and an MS in Aeronautical Engineering from the George Washington University in 1997. He has been a research engineer in the Crew Systems Branch for 15 years with an emphasis on advanced head-up display technologies; previously, he worked at Computer Science Corporation as a software developer for NASA's 737 research aircraft. 